Sādhanā Vol. 39, Part 3, June 2014, pp. 583-596. (C) Indian Academy of Sciences

\title{
Buckling analysis of rectangular composite plates with rectangular cutout subjected to linearly varying in-plane loading using fem
}

\author{
A LAKSHMI NARAYANA ${ }^{1}$, KRISHNAMOHANA RAO ${ }^{2, *}$ and \\ R VIJAYA KUMAR ${ }^{3}$
}
${ }^{1}$ HAL, Rotary Wing Research and Design Centre (RWR\&DC), Bangalore 560017 , India
${ }^{2}$ Department of Mechanical Engineering, JNTUH, Hyderabad 500 085, India
${ }^{3}$ Hindustan Aeronautics Limited, Rotary Wing Research and Design Centre
(RWR\&DC), Bangalore 560 017, India
e-mail:kmrgurram@jntuh.ac.in; alnarayana2005@gmail.com;
rvkumar1@yahoo.com

MS received 17 September 2012; revised 11 December 2013; accepted 24 January 2014;

\begin{abstract}
A numerical study is carried out using finite element method, to examine the effects of square and rectangular cutout on the buckling behavior of a sixteen ply quasi-isotropic graphite/epoxy symmetrically laminated rectangular composite plate $\left[0^{\circ} /+45^{\circ} /-45^{\circ} / 90^{\circ}\right]_{2 s}$, subjected to various linearly varying in-plane compressive loads. Further, this paper addresses the effects of size of square/rectangular cutout, orientation of square/rectangular cutout, plate aspect ratio(a/b), plate length/thickness ratio(a/t), boundary conditions on the buckling bahaviour of symmetrically laminated rectangular composite plates subjected to various linearly varying in-plane compressive loading. It is observed that the various linearly varying in-plane loads and boundary conditions have a substantial influence on buckling strength of rectangular composite plate with square/rectangular cutout.
\end{abstract}

Keywords. Buckling; rectangular cutout; linearly varying in-plane load; boundary conditions symmetrically laminated rectangular composite plates; finite element analysis; quasi-isotropic.

\section{Introduction}

In aeronautical, marine and automobile industries the use of composite laminates has increased due to their high stiffness and strength-to-weight ratios, long fatigue life, resistance to electrochemical corrosion and other superior material properties of composites. A true understanding of

*For correspondence 
structural behavior is essential. The buckling loads and modal characteristics, deflections as well as through-thickness distributions of stresses and strains are important for obtaining strong, reliable multi-layered structures and to examine the failure characteristics (Zhang \& Yang 2009). A very few studies have been carried out on buckling analysis of composite plates under non-linear compressive loads. It is essential to analyse plates subjected to non-uniform loading to understand their influence on the buckling behaviour (Jana \& Bhaskar 2006). Analysis of composite laminated plates is more difficult due to anisotropic and heterogeneous nature of composite materials. Buckling of rectangular composite plates with rectangular cutouts has rarely been examined. To produce lighter and more efficient structures, cutouts are often required in structural components. For instance, Commercial transport aircraft wings and military fighter aircraft wings require cutouts in wing spars and cover panels to provide access for hydraulic lines, electrical lines and for damage inspection (Topal \& Uzman 2008).

Jana \& Bhaskar (2006) carried out a buckling analysis of a simply supported rectangular plate without cutout subjected to various types of non-uniform compressive loads. Chai et al (1993) investigated the influence of boundary conditions, plate aspect ratios on the optimal ply angle and associated optimal buckling loads of anti-symmetrically laminated composite plates without cutout under various linearly varying in-plane loading conditions. Hu et al (2003) examined the buckling behaviour of a graphite/epoxy symmetrically laminated composite rectangular plate without cutout under parabolic variation of axial loads. Nemeth (1997) investigated buckling analysis of infinitely long symmetrically laminated graphite/epoxy composite plates without cutout subjected to linearly varying edge loads, uniform shear loads or combination of these loads. Zhong \& Gu (2007) examined the effects of plate aspect ratios, load intensity variation and layup configuration on the buckling behavior of simply supported symmetrical cross-ply composite rectangular plates without cutout. Panda \& Ramachandra (2010) studied the effects of boundary conditions, non-uniform in-plane loading, plate aspect ratio and length/thickness ratio on the buckling behavior of rectangular composite plates without cutout.

Leissa \& Kang (2002), Kang \& Leissa (2005) presented the exact solutions for buckling analysis of rectangular plates without cutout having two opposite edges simply supported when these edges are subjected to linearly varying loads and the other two edges may be clamped, simply supported or free. The above studies deal with buckling analysis of composite plate without cutout or continuous plates. Hu \& Lin (1995) carried out numerical analysis using ABAQUS finite element program to examine the influence of end conditions and circular cutouts on the optimal fiber orientations and the associated optimal buckling loads of symmetrically laminated composite plates under uni-axial compression load. Hu \& Chen (1999) carriedout numerical analysis using ABAQUS finite element program to examine the influence of end conditions aspect ratios, circular cutouts, lateral loads on the optimal fiber orientations and the associated optimal buckling loads of un-symmetrically laminated plates under uni-axial compression load. Baba (2007); (Baba \& Baltaci 2007) carried out a buckling analysis of rectangular composite laminates under uni-axial compression load with a central circular hole to determine the effects of anti-symmetric laminate configuration and length/thickness ratio, boundary conditions on the buckling. The above studies - deal with buckling analysis of composite plate with circular cutout under uniform compression load using FEM.

Dinesh \& Singh (2010) examined the effects of boundary conditions on buckling and post buckling behaviour of uni-axially compressed quasi-isotropic laminated plate with various shaped cutouts of various sizes using the finite element method. Eiblmeier \& Loughlan (1995, 1997) used finite element method to investigate the effect of different sized cutouts, with and without various types of reinforcement's boundary conditions and width of the circular reinforcement rings on the buckling behaviour of symmetrically laminated CFRP square panels 
loaded in pure shear or in uni-axial compression load. Guo (2007), (Guo \& Cheung 2008) used finite element method to investigate the effect of reinforcements around circular cutouts on the stress concentration and buckling behaviour of symmetrically laminated carbon/epoxy composite panel under in-plane shear load. Above studies deal with buckling analysis of composite plates with reinforced circular cutouts under shear load. Using finite element method (Altan \& Kartal 2009) examined buckling analysis of symmetrically laminated cross-ply reinforced concrete plates with a central rectangular hole under biaxial uniform in-plane loadings.

Husam et al (2009) carried out buckling analysis of square composite plates with circular cutout to investigate the effects of cutout size, cutout location, fibre orientation angle and type of loading on the buckling load. Ameen (2009) used finite element method to examine the effect of the cutout shapes, sizes, radii of corner of cutout and number of layers on the buckling load of the fiber reinforced polyester composite laminated plate. Srivatsa \& Murthy (1992) determined the effects of boundary conditions, fibre orientations, circular cutout sizes on the buckling load of fibre-reinforced plastic square panels using finite element method. Ghannadpour et al (2006) examined the effect of a cutout on the buckling behaviour of symmetric cross-ply polymer matrix rectangular composites subjected to uniform compression load using finite element method. Using finite element method Jain \& Ashwin (2004) investigated the effects of the cutout shape, size and the alignment of the elliptical cutout on the buckling and the first-ply failure loads of square laminates subjected to uni-axial compression load.

Using a semi-analytical extended Kantorovich approach method Shufrin et al (2008a, b) performed buckling analysis of symmetrically laminated rectangular plates subjected to in-plane shear, compression and tension loads. Singh \& Ashwin (1998) carried out the post buckling response and progressive failure of thin, symmetric rectangular laminates subjected to in-plane shear loads with various lay-ups and plate aspect ratios using finite element method. Using finite element method (Aydin Komur et al 2010) investigated the effects of an elliptical/circular cutout on the buckling load of symmetric cross-ply and angle-ply laminate square composite plates. The above studies deal with buckling analysis of composite plate with elliptical or circular cutout subjected to uniform compression load using FEM.

The results presented in the literature indicate that the effect of cutout shape, orientation of the cutout, plate aspect ratio(a/b), length/thickness ratio(a/t), boundary conditions and various linearly varying in-plane compressive loads on the buckling behaviour of rectangular composite plates are needed to investigate in more detail.

In this paper the effect of square and rectangular cutouts on the buckling behaviour of quasi-isotropic graphite/epoxy symmetrically laminated rectangular composite plates subjected various linearly varying in-plane compressive loading is examined using FEM. This study also contains the effect of cutout orientation angle $\beta$, different sizes of cutout, plate aspect ratio $(\mathrm{a} / \mathrm{b})$ and plate length/thickness ratio $(\mathrm{a} / \mathrm{t})$ and boundary conditions on the buckling behaviour of rectangular composite plates with square/rectangular cutout subjected to various linearly varying in-plane compressive loads.

\section{Present study}

In this study, a numerical study using finite element method has been carried out to investigate the effect of square and rectangular cutouts on the buckling response of quasi-isotropic $\left[0^{\circ} /+45^{\circ} /-45^{\circ} / 90^{\circ}\right]_{2 s}$ graphite/epoxy symmetrically laminated rectangular composite plates subjected to various linearly varying in-plane compressive loading. Furthermore, the effects of plate aspect ratio $(\mathrm{a} / \mathrm{b})$, plate length/thickness ratio $(\mathrm{a} / \mathrm{t})$, cutout orientation angle $\beta$, size of cutout, 
boundary conditions on the buckling response of quasi-isotropic graphite/epoxy symmetrically laminated rectangular composite plates with square/rectangular cutouts under various in-plane compressive loading has been investigated. In military aircraft and civil aircraft industry the most laminates used are symmetric configuration since all the bending-extension coupling stiffnesses will become zero. Because of the elimination of coupling between extension and bending in symmetric laminates, a tendency to bend or twist that occur during cooling following the curing process while manufacturing the composites can be eliminated. That is why the symmetric laminates are selected in this (Jones 1999).

The lamina consists of epoxy as matrix material and graphite fibers as reinforcement material. In table 1, the material properties of graphite/epoxy are listed (Hu \& Lin 1995). The various linearly varying compressive loads applied on plate coincide with global $\mathrm{x}$-axis. The $0^{\circ}$ fibre direction is aligned with the direction of the compressive load.

Figure 1 shows the geometry of the model. The width ' $b$ ' and length ' $a$ ' of the plate are $100 \mathrm{~mm}$ and $200 \mathrm{~mm}$, respectively. The thickness of each layer of this sixteen layer laminated composite plate is $0.125 \mathrm{~mm}$ and ' $\mathrm{t}$ ' is the thickness of the composite plate. In this study the cutout shape was assumed rectangular hole and placed in the center of the rectangular plate. The length of the cutout denoted by 'c' and width of the cutout denoted by 'd'. To study the effect of square and rectangular hole, the parameters $\mathrm{c}$ and $\mathrm{d}$ are changed to selected ratios. When the ratios $\mathrm{c} / \mathrm{b}$ and $\mathrm{d} / \mathrm{b}$ are equal, the rectangular hole becomes square hole. Buckling analysis is carried out briefly for both various square and rectangular holes. When the ratios $\mathrm{c} / \mathrm{b}=0$ or $\mathrm{d} / \mathrm{b}$ $=0$, the laminated plate becomes plate without cutout. The laminated plates are also examined to determine the effect of having a cutout and without a cutout conditions on buckling loads.

\section{Finite element modelling}

In this study buckling load of a rectangular composite plate with rectangular/square cutout is predicted using the Eigen buckling analysis in ANSYS. The elements used in numerical analysis to model the plate are eight noded SHELL 281 shell elements. The shell element SHELL 281 (Release 10.0 Documentation for ANSYS) has 6 degrees of freedom at each node (3 displacements and 3 rotations). Due to different cutout dimensions and cutout orientation angles, different models and mesh structures are made. Figure 2 shows the typical finite element mesh of the model and boundary conditions of the model. As seen from figure 2, small meshes are made in the vicinity of the rectangular/square cutout where large stress concentrations are predicted.

The boundary conditions have a significant influence on the buckling behavior of quasiisotropic graphite/epoxy symmetrically laminated rectangular composite plate with rectangular/square cutout subjected to various linearly varying in-plane compressive loads. In this study the quasi-isotropic rectangular composite plate is evaluated at two different boundary conditions. Two types of boundary conditions, namely CC and CS are considered; CC refers to a plate with two longitudinal edges $(\mathrm{x}=0$ and $\mathrm{x}=\mathrm{a})$ clamped and the other two edges free (i.e $\mathrm{y}=0$ and $y=b)$ and CS refers to a plate with one edge $(x=0)$ clamped, other edge $(x=a)$ simply

Table 1. Material properties of the graphite/epoxy composite material (Hu \& Lin 1995).

\begin{tabular}{lcccc}
\hline $\mathrm{E}_{11}(\mathrm{GPa})$ & $\mathrm{E}_{22}(\mathrm{GPa})$ & $\mathrm{v}_{12}$ & $\mathrm{G}_{12}=\mathrm{G}_{13}(\mathrm{GPa})$ & $\mathrm{G}_{23}(\mathrm{GPa})$ \\
\hline 128 & 11 & 0.25 & 4.48 & 1.53 \\
\hline
\end{tabular}




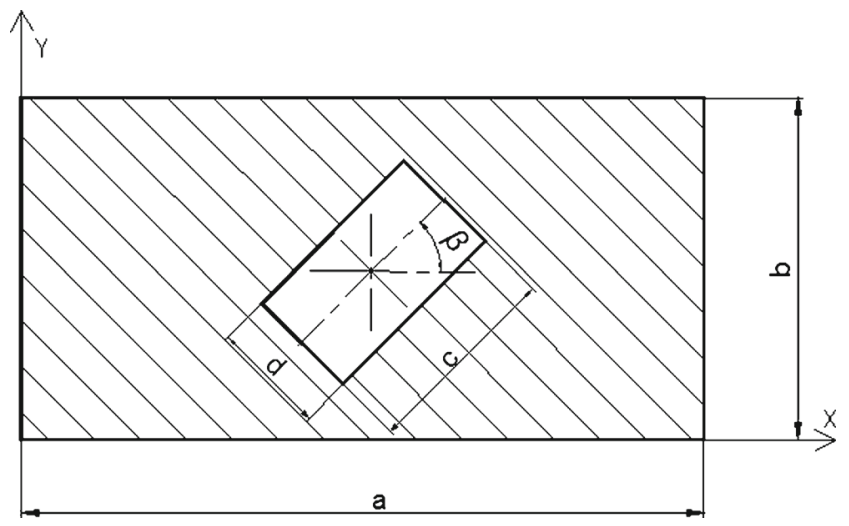

Figure 1. Geometry of the model.

supported and the other two edges free (i.e $y=0$ and $y=b$ ). Seven types of loading conditions are considered, namely L1, L2, L3, L4, L5, L6 and L7 which are shown figure 3. $\mathrm{N}_{0}$ is intensity of compressive force at the plate edge $(x=a)$ from $y=0$ to $y=b$ for loading case L1; intensity of compressive force at the plate edge $(x=a)$ and $a t y=b$ for loading case L2,L3,L4 and L5; intensity of compressive force at the plate edge $(x=a)$ and at $y=0$ for loading case L6 and L7.

\section{Verification of results}

The accuracy of the method is verified by comparing buckling loads with the results available in literature. Table 2 shows a comparison of buckling loads of present study and available in literature. For comparison purpose, material properties, laminate dimensions and boundary conditions were similar to reference (Hu \& Lin 1995). The results obtained in this study are in good agreement with the results available in literature.

\section{Results and discussion}

5.1 Effect of boundary conditions, various linearly varying in-plane compressive loading, cutout orientation $\beta$ as well as $c / b, d / b$ ratios on buckling load of a composite plate with rectangular cutout

This section deals with the effects of boundary conditions, various linearly varying in-plane compressive loading, cutout orientation $\beta$ as well as $\mathrm{c} / \mathrm{b}$ and $\mathrm{d} / \mathrm{b}$ ratios on the buckling loads of a rectangular composite plate with rectangular cutout. Figures $4 \mathrm{a}$ and $\mathrm{b}$, indicate that that the buckling loads of a rectangular composite plate with rectangular cutout are decreased by increasing cutout orientation $\beta$ irrespective of boundary conditions and various linearly varying in-plane compressive loading conditions. As the projected area of the cutout perpendicular to applied load increases buckling load decreases. When cutout orientation angle becomes $90^{\circ}$ projected area of cutout perpendicular to load becomes the maximum and buckling load becomes minimum. According to figures $4 \mathrm{a}$ and $\mathrm{b}$, when rectangular cutout orientation $\beta=0^{\circ}$, buckling load of 
(a)

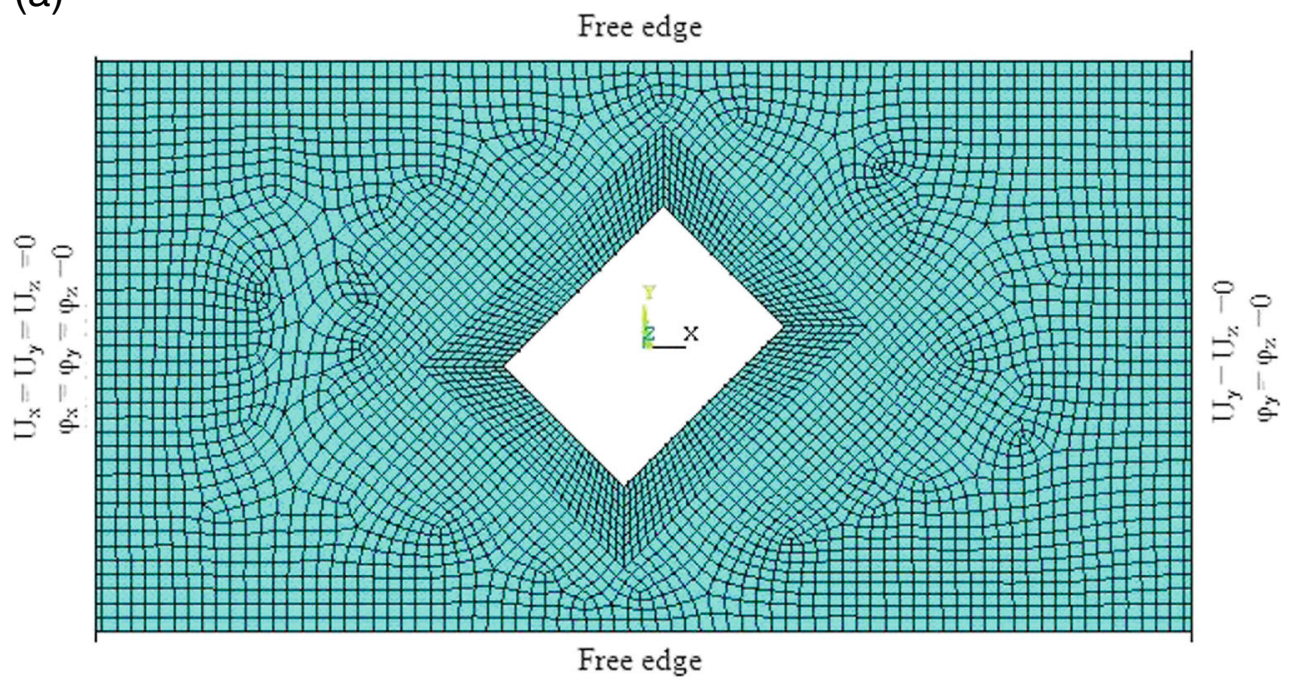

CC type boundary condition

(b)

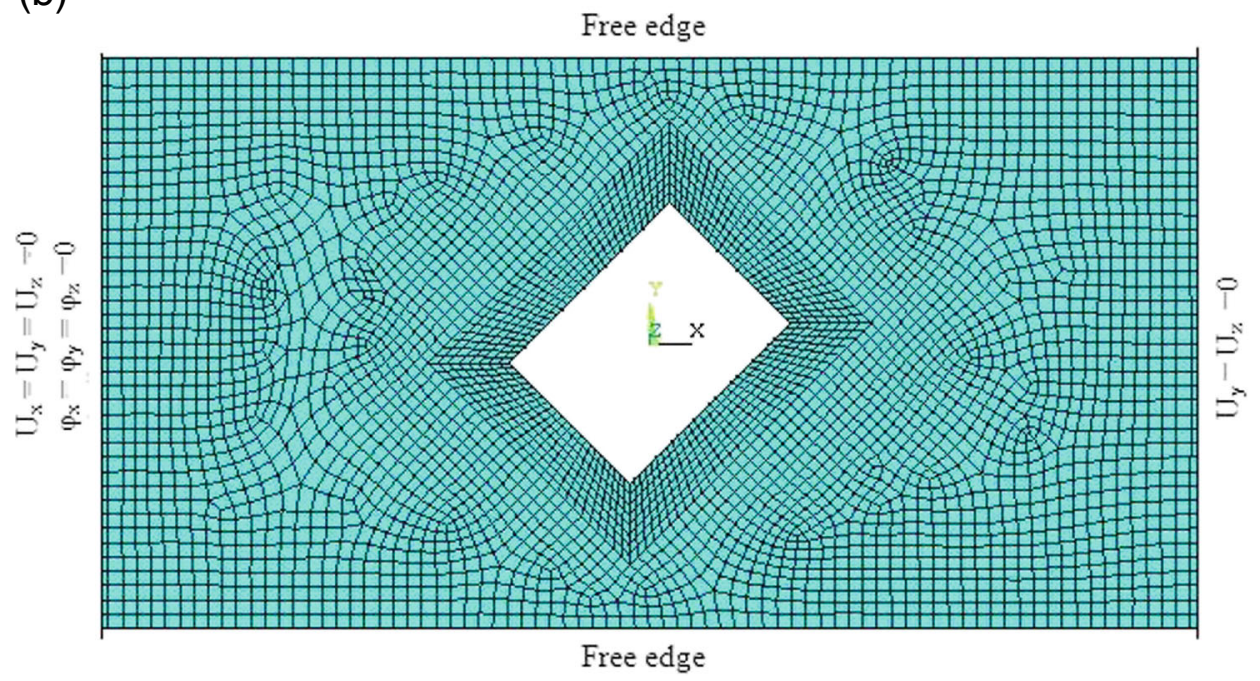

CS type boundary condition

Figure 2. Boundary conditions and finite element mesh of the laminated plate. (a) CC type boundary condition, (b) CS type boundary condition.

the plate becomes maximum and when rectangular cutout orientation $\beta=90^{\circ}$, buckling load of the plate becomes minimum, for all loading conditions and boundary conditions.

Further, the decreasing of buckling loads is very fast between $\beta=15^{\circ}$ and $75^{\circ}$ and very slow between $\beta=0^{\circ}$ and $15^{\circ}$ as well as between $\beta=75^{\circ}$ and $90^{\circ}$. The decrease in buckling load by increasing rectangular cutout orientation $\beta$ from $0^{\circ}$ to $90^{\circ}$ is $12 \%$ for all loads. As the size 

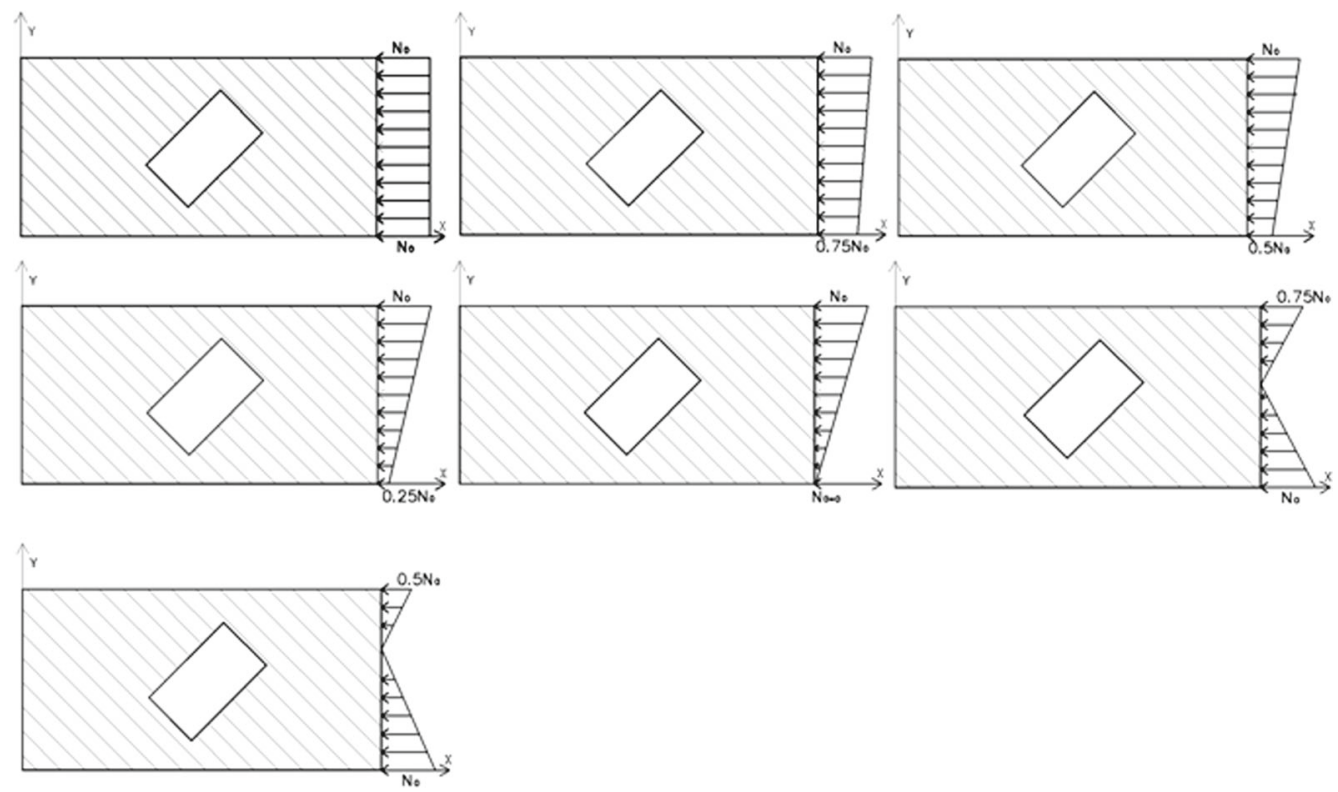

Figure 3. Details various loading conditions.

of the rectangular cutout increases the effect of cutout orientation $\beta$ on the buckling strength of rectangular composite plate increases.

Figures $4 \mathrm{c}$ and $\mathrm{d}$ reveal that the buckling loads of a rectangular composite plate with rectangular cutout are decreased by increasing $\mathrm{c} / \mathrm{b}$ and $\mathrm{d} / \mathrm{b}$ ratios irrespective of boundary conditions and various linearly varying in-plane compressive loading conditions. According to figure $4 \mathrm{c}$ and $\mathrm{d}$, the reduction in buckling load is very fast when keeping the length of the cutout 'c' constant and increasing the width of the cutout ' $d$ '. Furthermore, the reduction in buckling load is very slow when keeping the width of the cutout ' $\mathrm{d}$ ' constant and increasing the length of the cutout 'c'. As seen from the figure $4 \mathrm{c}$ and $\mathrm{d}$, the influence of $\mathrm{c} / \mathrm{b}$ ratio on the reduction of the buckling load is less than the $d / b$ ratio. That is, the length of the cutout aligned with the load has lesser influence than the width of the cutout (d) perpendicular to the load. For a rectangular plate with rectangular cutout i.e $\mathrm{d} / \mathrm{b}=0.1$ and $\beta=0$, the reduction in buckling load by increasing $\mathrm{c} / \mathrm{b}$ from 0 to 0.4 is $5 \%$. For a rectangular plate with rectangular cutout that is $\mathrm{c} / \mathrm{b}=0.1$ and $\beta=0$, the reduction in buckling load by increasing $\mathrm{c} / \mathrm{b}$ from 0 to 0.4 is $22 \%$.

Boundary conditions have higher influence on the buckling load of rectangular composite plate. The buckling load for the plate with CC type boundary condition is higher than the

Table 2. Comparison of buckling loads of composite plates under uniaxial compression load with $\left[40^{\circ} /+40^{\circ} / 90^{\circ} / 0^{\circ}\right]_{2 s}$ laminate lay-up and with two simply supported ends and two fixed ends.

\begin{tabular}{llcc}
\hline \multirow{2}{*}{ Reference } & Type of plate & \multicolumn{2}{c}{ Buckling load (in KN/cm) } \\
\cline { 3 - 4 } Hu \& Lin 1995 & Rectangular plate $\mathrm{a} / \mathrm{b}=2$ & In reference (ABAQUS) & In present study (ANSYS) \\
\cline { 2 - 4 } & Rectangular plate $\mathrm{a} / \mathrm{b}=2$, & 3.3 & 2.4 \\
& $\mathrm{c} / \mathrm{b}=0.8$ and $\mathrm{d} / \mathrm{b}=0.8$ & & 3.2 \\
\hline
\end{tabular}



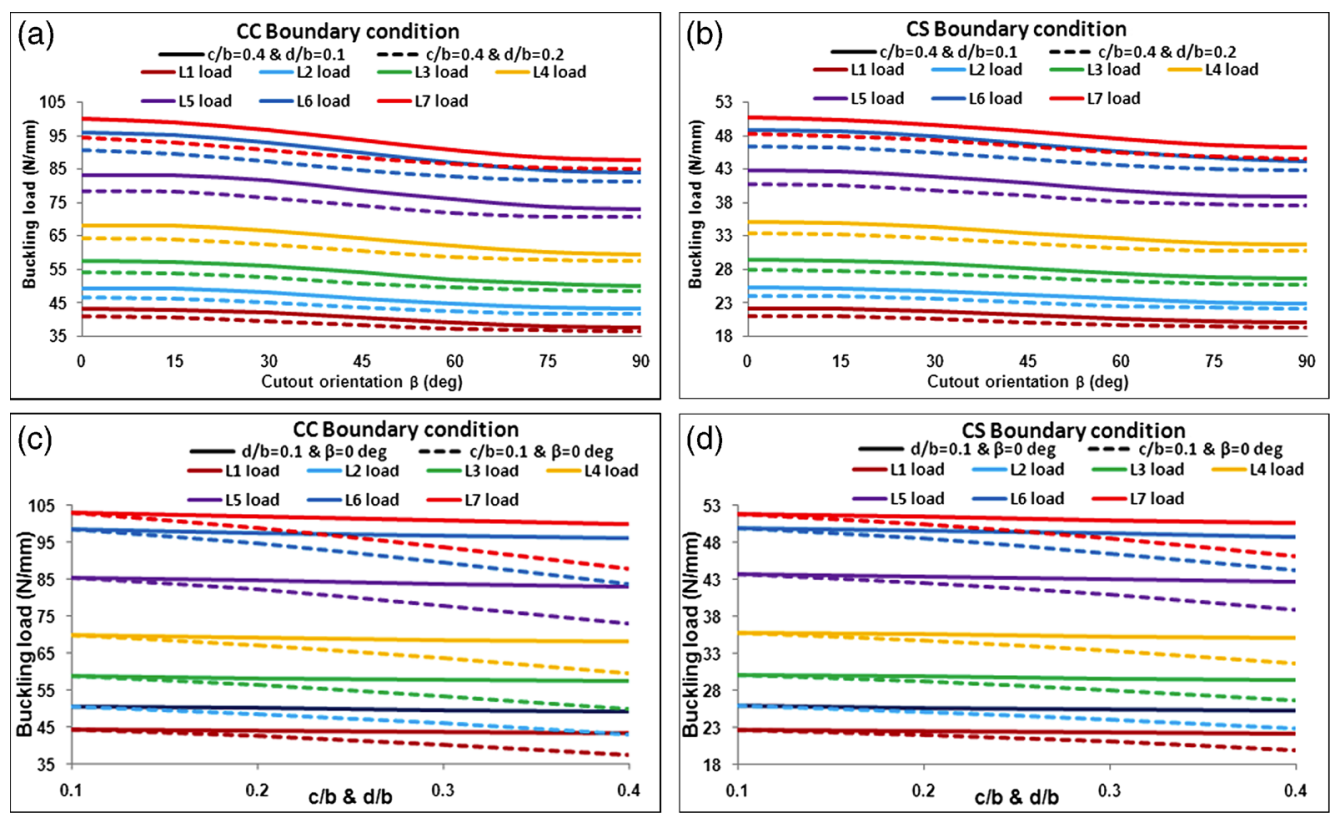

Figure 4. Effect of boundary conditions, various linearly varying in-plane compressive loading, cutout orientation $\beta$ and $\mathrm{c} / \mathrm{b}, \mathrm{d} / \mathrm{b}$ ratios on buckling load of composite plate with rectangular cutout.

buckling load for the same plate with CS type boundary condition irrespective of cutout size and various linearly varying in-plane compressive loading conditions. As the edge support becomes rigid buckling strength increases. From figures $4 \mathrm{a}, \mathrm{b}, \mathrm{c}$ and d, it is understood that the buckling load of rectangular composite plate with CC type boundary condition is two times of the buckling load of the composite plate with CS type boundary condition.

Figures $4 \mathrm{a}, \mathrm{b}$, c and d reveal that the buckling load of the rectangular composite plate with L7 type loading condition is higher than those under L1, L2, L3,L4,L5 and L6 type loading conditions, irrespective of cutout shape, size, orientation of cutout and boundary conditions. The second important point from the figures $4 \mathrm{a}, \mathrm{b}, \mathrm{c}$ and $\mathrm{d}$ is that the buckling load of the rectangular composite plate with L7,L6, L5, L4, L3 and L2 type loading condition is approximately $2.3 \times$, $2.2 \times, 1.9 \times, 1.5 \times, 1.3 \times$ and $1.1 \times$ of the buckling load of the same composite plate with L1 type loading condition, respectively, for the same size, orientation of cutout and boundary condition. When designing a structure, buckling strength can be estimated for uniform compression load which will have lowest buckling strength compared to various linearly varying in-plane loads, to get reliable structure and to cater for any type of load.

\subsection{Effect of boundary conditions, various linearly varying in-plane compressive loading as well as cutout orientation $\beta$ on buckling load of a composite plate with square cutout}

This section deals with the effects of boundary conditions, various linearly varying in-plane compressive loading, cutout orientation $\beta$ on the buckling loads of a rectangular composite plate with square cutout.

Figure $5 \mathrm{a}$ and $\mathrm{b}$ reveal that the buckling loads of a rectangular composite plate with square cutout are decreased when the cutout orientation $\beta$ is increased from 0 to $45^{\circ}$ and again buckling 

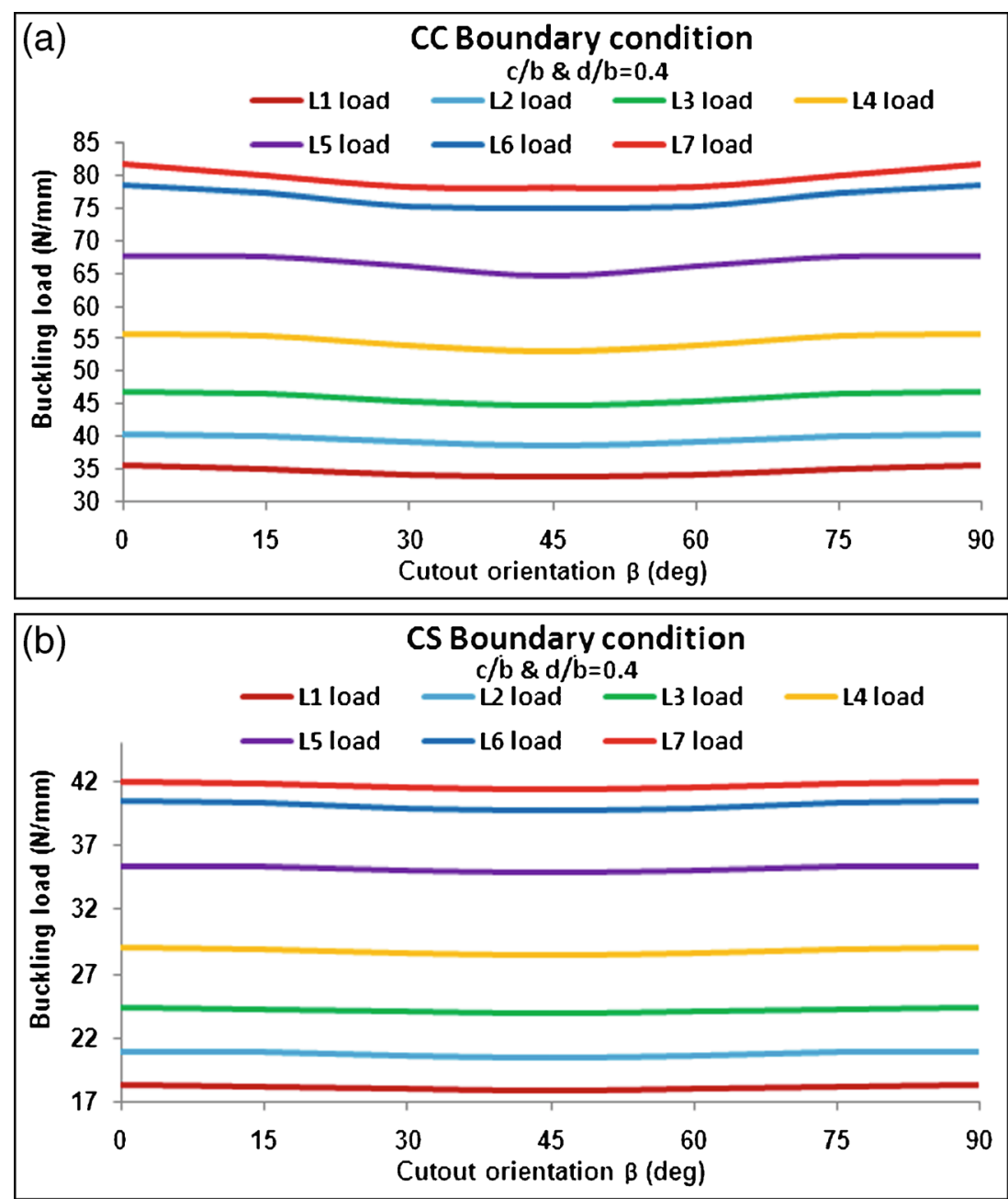

Figure 5. Effect of boundary conditions, various linearly varying in-plane compressive loading and cutout orientation $\beta$ on buckling load of composite plate with square cutout.

loads are increased when the cutout orientation $\beta$ is increased from 45 to $90^{\circ}$, irrespective of boundary conditions and various linearly varying in-plane compressive loading conditions. As the projected area of the cutout perpendicular to applied load increases buckling load decreases. When square cutout orientation angle becomes $45^{\circ}$ projected area of cutout perpendicular to load becomes maximum and buckling load becomes minimum. According to figures $5 \mathrm{a}$ and $\mathrm{b}$, when square cutout orientation $\beta=0$ and $90^{\circ}$, buckling load of the plate becomes maximum and when square cutout orientation $\beta=45^{\circ}$, buckling load of the plate becomes minimum, for all loading conditions and boundary conditions. Further the decreasing of buckling loads is very sluggish between 0 to $15^{\circ}$ and it is very quick between 15 to $45^{\circ}$. The increase of buckling load is very quick between 45 to $75^{\circ}$ and it is very sluggish between 75 to $90^{\circ}$. The decrease in buckling load by increasing square cutout orientation $\beta$ from 0 to $45^{\circ}$ is $5 \%$ for all loads. 


\subsection{Effect of the plate aspect ratio $(a / b)$ on buckling load}

This section deals with the effect of plate aspect ratio $(\mathrm{a} / \mathrm{b})$, boundary conditions and various linearly varying in-plane compressive loading on the buckling behaviour of quasi-isotropic symmetrically laminated rectangular composite plates with rectangular cutout. In this section the length of the plate ' $a$ ' is varied between $200 \mathrm{~mm}$ and $400 \mathrm{~mm}$ the width of the plate ' $\mathrm{b}$ ' is $100 \mathrm{~mm}$. Plate aspect ratios $(\mathrm{a} / \mathrm{b})$ selected in this study $(\mathrm{a} / \mathrm{b})$ are $2,2.5,3,3.5$ and 4 . As seen from figures $6 a$ and $b$, buckling loads decrease as the plate aspect ratios increase, irrespective of boundary conditions and various linearly varying in-plane compressive loading.

According to figure $6 a$ and $b$, The buckling load of the rectangular composite plate with plate with plate aspect ratio $\mathrm{a} / \mathrm{b}=2$ is approximately 1.5 times, 2 times, 3 times and 4 times of the buckling load of the plate with plate aspect ratio $2.5,3,3.5$ and 4 , respectively, for all boundary
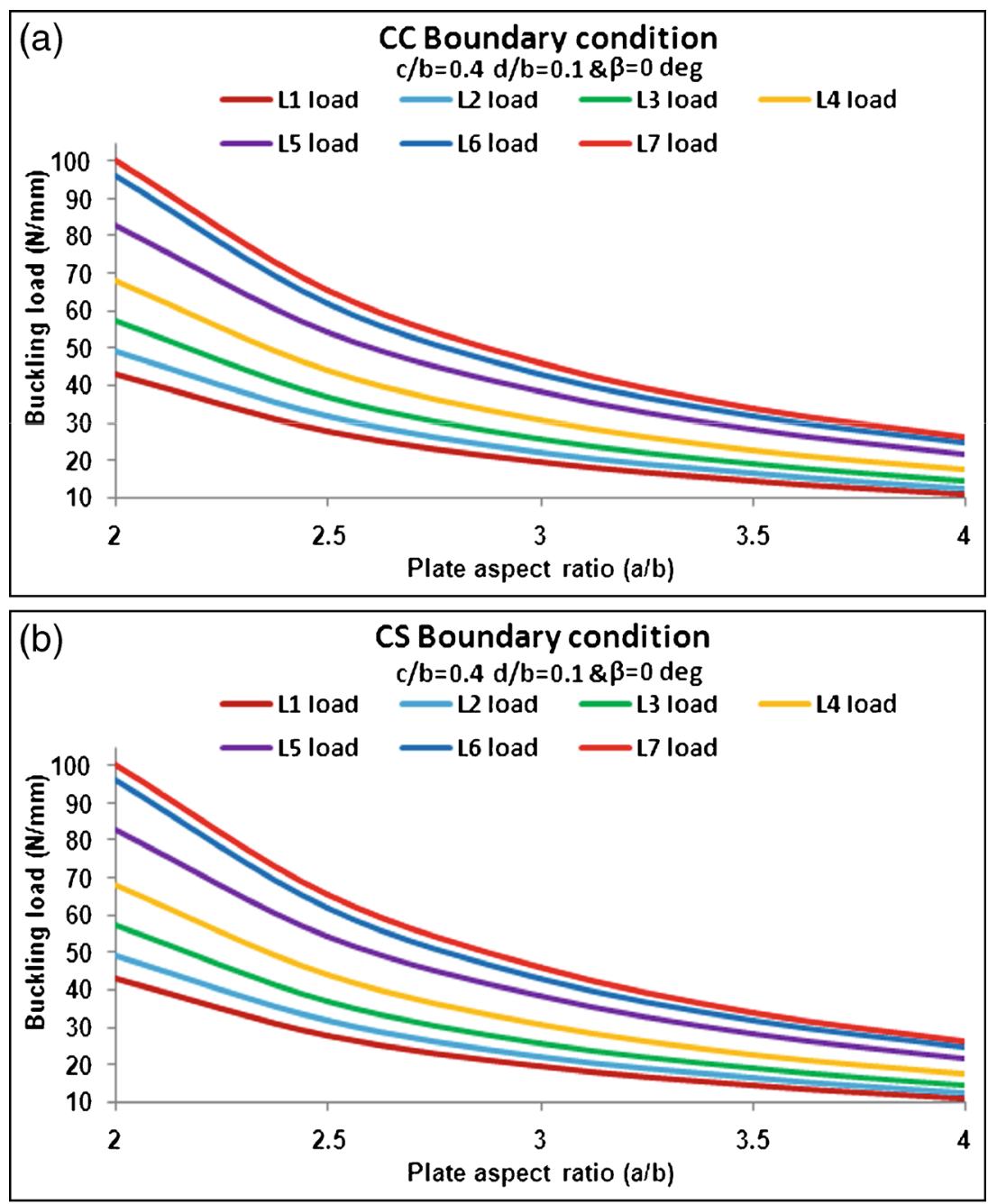

Figure 6. Effect of plate aspect ratio $(\mathrm{a} / \mathrm{b})$, boundary conditions and various linearly varying in-plane loading on buckling load. 
conditions and various linearly varying in-plane compressive loading. The second important point from the figures $6 \mathrm{a}$ and $\mathrm{b}$ is that the rate of reduction in buckling load is very slow between plate aspect ratios $(\mathrm{a} / \mathrm{b})=3 \& 4$ compared to plate aspect ratios $(\mathrm{a} / \mathrm{b})=2$ and 3 . As seen from the figures $6 \mathrm{a}$ and $\mathrm{b}$, as the plate aspect ratio $(\mathrm{a} / \mathrm{b})$ ratio increases from 2 to 4 , decrease in buckling load is $75 \%$. In other words, buckling load is reduced by $75 \%$ due to the $100 \%$ increase in a/b ratio.

\subsection{Effect of length/thickness ratio (a/t) on buckling load}

This section discusses the effect of length/thickness ratio (a/t), boundary conditions and various linearly varying in-plane compressive loading conditions on the buckling behaviour of quasiisotropic rectangular composite plate $\left[0^{\circ} /+45^{\circ} /-45^{\circ} / 90^{\circ}\right]_{2 s}$, with rectangular cutout. The plate
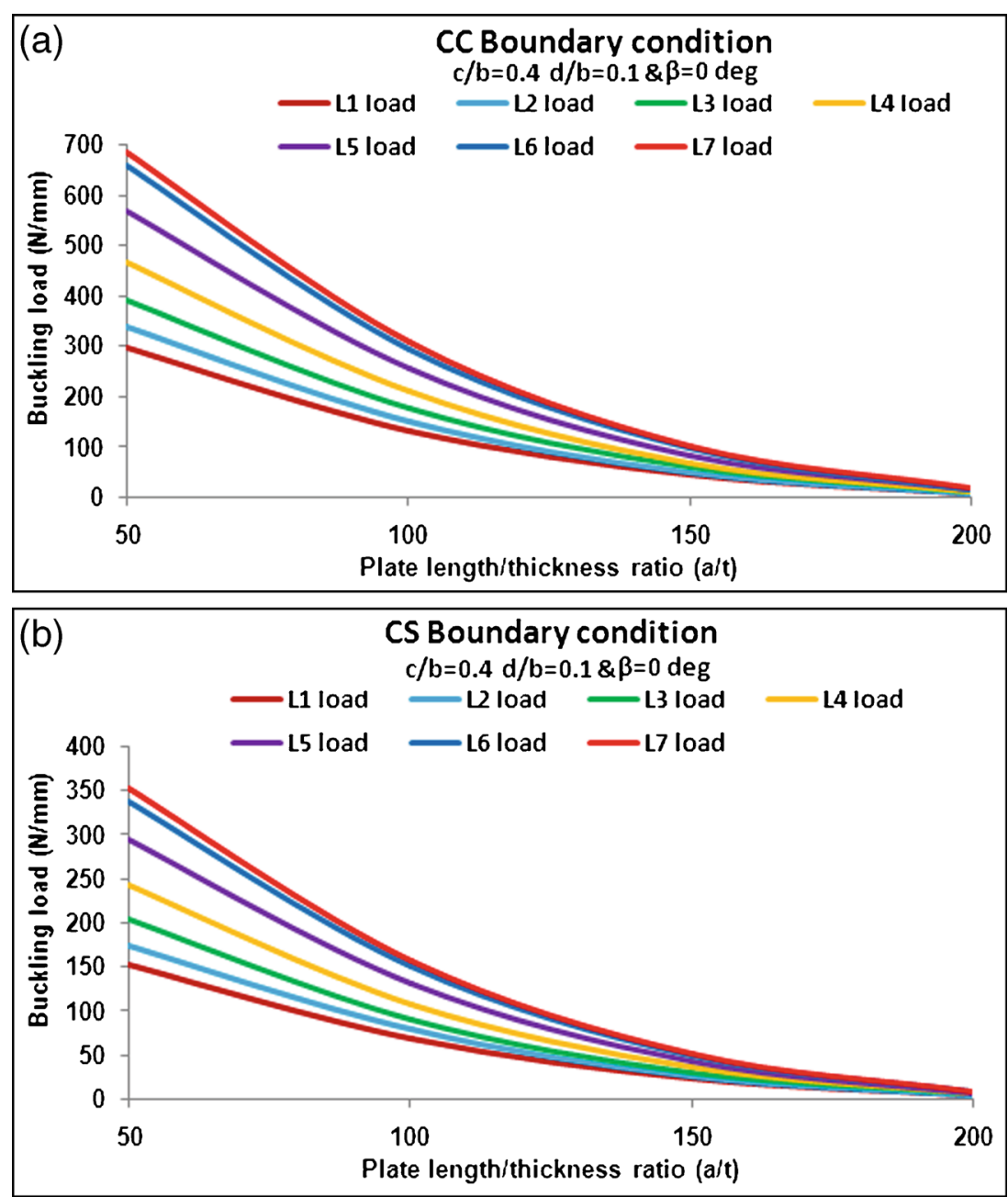

Figure 7. Effect of plate length/thickness ratio $(\mathrm{a} / \mathrm{t})$, boundary conditions and various linearly varying in-plane loading on buckling load. 
length/thickness ratios (a/t) selected in this study are 50, 66.66, 100 and 200. In this section the length of the plate 'a' taken as $200 \mathrm{~mm}$ and width of the plate is $100 \mathrm{~mm}$. Thickness of the plate ' $\mathrm{t}$ ' taken as $1 \mathrm{~mm}$ (8 layers), $2 \mathrm{~mm}$ (16 layers), $3 \mathrm{~mm}$ (24 layers) and $4 \mathrm{~mm}$ (32 layers). The thickness of each layer is $0.125 \mathrm{~mm}$. As seen from figures $7 \mathrm{a}$ and $\mathrm{b}$ as length/thickness $(\mathrm{a} / \mathrm{t})$ ratio increases the buckling load decreases, irrespective of boundary conditions and various linearly varying in-plane compressive loading conditions.

According to figures $7 \mathrm{a}$ and $\mathrm{b}$, the buckling load of the composite plate $\left[0^{\circ} /+45^{\circ} /\right.$ $\left.45^{\circ} / 90^{\circ}\right]_{2 s}$ with plate length/thickness (a/t) ratio 50 (32 layers) is approximately 2 times, 7 times and 43 times of the buckling load of the same plate with (a/t) ratio 66.6 (24 layers), 100(16 layers) and 200 (8 layers), respectively, irrespective of various linearly varying in-plane compressive loading and boundary conditions. The second important point from the figures $7 \mathrm{a}$ and $7 \mathrm{~b}$ is that the rate of reduction in buckling load is slow between plate length/thickness ratios $(\mathrm{a} / \mathrm{t}) 100(16$ layers) and 200 (8 layers)compared to plate length/thickness ratios (a/t) 50(32 layers) and 100 (16 layers) . From the figures $7 \mathrm{a}$ and $\mathrm{b}$, the buckling load of the rectangular composite plate with rectangular cutout under $\mathrm{CC}$ boundary condition is 2 times of the same plate under CS boundary condition, for all $\mathrm{a} / \mathrm{t}$ ratios. As seen from the figures $7 \mathrm{a}$ and $\mathrm{b}$, as the plate length/thickness $(\mathrm{a} / \mathrm{t})$ ratio increases from 50 to 200, decrease in buckling load is $97 \%$.in other words, buckling load is reduced by $97 \%$ due to the $300 \%$ increase in a/t ratio.

\section{Conclusions}

On the basis of the present study, which has dealt with the effect of boundary conditions and various linearly varying in-plane compressive loading conditions on the buckling behaviour of a sixteen ply quasi-isotropic graphite/epoxy symmetrically laminated rectangular composite plate $\left[0^{\circ} /+45^{\circ} /-45^{\circ} / 90^{\circ}\right]_{2 s}$, with square/rectangular cutout, the following conclusions are drawn:

(1) For a rectangular composite plate with rectangular cutout, the magnitudes of buckling loads are decreased by increasing of cutout orientation angle $\beta$ from 0 to $90^{\circ}$, irrespective of boundary conditions and various linearly varying in-plane compressive loading conditions.

(2) For a rectangular composite plate with square cutout, the magnitudes of buckling loads are decreased by increasing of cutout orientation angle $\beta$ from 0 to $45^{\circ}$ and are increased by increasing of cutout orientation angle $\beta$ from 45 to $90^{\circ}$, irrespective of boundary conditions and various linearly varying in-plane compressive loading conditions.

Furthermore the effect of cutout orientation $\beta$ on the buckling of rectangular composite plate increases as the cutout size increases.

(3) The magnitudes of buckling loads are decreased by increasing of $\mathrm{c} / \mathrm{b}, \mathrm{d} / \mathrm{b}$ ratios, irrespective of boundary conditions and various linearly varying in-plane compressive loading conditions. The influence of $\mathrm{d} / \mathrm{b}$ ratio on the reduction of the buckling load is more than the $\mathrm{c} / \mathrm{b}$ ratio. That is, the width of the cutout (d) perpendicular to the load has much higher influence than the length of the cutout aligned with the load.

(4) The buckling load of quasi-isotropic rectangular composite plate is highly influenced by its boundary conditions. The buckling load of the rectangular composite plate with CC (clamped-clamped) type boundary condition is 2 twice that of the buckling load of the composite plate with CS (clamped-simply supported) type boundary condition, irrespective various linearly varying in-plane compressive loading conditions. 
(5) The magnitude of the buckling load for the composite plate under L7 type loading condition is higher than those under L1, L2, L3, L4, L5 and L6 type loading for all boundary condition. The buckling load of the rectangular composite plate with L7, L6, L5, L4, L3 and L2 type loading condition is approximately 2.3 times, 2.2 times, 1.9 times, 1.5 times, 1.3 times and 1.1 times of the buckling load of the same composite plate with L1 type loading condition, respectively, for all boundary conditions.

(6) The magnitudes of buckling loads are decreased by increasing the plate aspect ratio (a/b), irrespective of boundary conditions and various linearly varying in-plane compressive loading conditions. The buckling load of the rectangular composite plate with plate with plate aspect ratio $\mathrm{a} / \mathrm{b}=2$ is approximately 1.5 times, 2 times, 3 times and 4 times of the buckling load of the plate with plate aspect ratio $2.5,3,3.5$ and 4, respectively, for all boundary conditions and various linearly varying in-plane compressive loading. Buckling load reduces by $75 \%$ due to the $100 \%$ increase in $\mathrm{a} / \mathrm{b}$ ratio.

(7) As the plate length/thickness ( $\mathrm{a} / \mathrm{t})$ ratio increases the buckling load decreases, irrespective of boundary conditions and various linearly varying in-plane compressive loading conditions. The buckling load of the rectangular composite plate with length/thickness (a/t) ratio 50 (32 layers) is approximately 2 times, 7 times and 43 times of the buckling load of the plate with (a/t) ratio 66.6 (24 layers), 100 (16 layers) and 200 (8 layers), respectively. Buckling load reduce by $97 \%$ due to the $300 \%$ increase in a/t ratio.

\section{References}

Altan M F and Kartal M E 2009 Investigation of buckling bahaviour of laminated reinforced concrete plates with central rectangular hole using finite element method. Mater. Des. 30: 2243-2249

Ameen H A 2009 Buckling analysis of composite laminated plate with cutouts. Eng. Tech. J. 27: 16111621

Aydin Komur M, Sen F, Atas A and Arslan N 2010 Buckling analysis of laminated composite plates with an elliptical/circular cutout using FEM. Adv. Eng. Soft. 41: 161-164

Baba B O 2007 Buckling behaviour of laminated composite plates. J. Reinf. Plast. Compos. 26: 1637-55

Baba B O and Baltaci A 2007 Buckling characteristics of symmetrically and antisymmetrically laminated composite plates with central cutout. Appl. Compos. Mater. 14: 265-276

Chai G B, Ooi K T and Khong P W 1993 Buckling strength optimization of laminated composite plates. Comput. Struct. 46: 77-82

Dinesh K and Singh S B 2010 Effects of boundary conditions on buckling and postbuckling responses of composite laminate with various shaped cutouts. Compos. Struct. 92: 769-779

Eiblmeier J and Loughlan J 1995 The buckling response of carbon fibre composite panels with reinforced cutouts. Compos. Struct. 32: 97-113

Eiblmeier J and Loughlan J 1997 The influence of reinforcement ring width on the buckling response of carbon fibre composite panels with circular cutouts. Compos. Struct. 38: 609-622

Ghannadpour S A M, Najafi A and Mohammadi B 2006 On the buckling bahaviour of cross-ply laminated composite plates due to circular/elliptical cutouts. Compos. Struct. 75: 3-6

Guo S J 2007 Stress concentration and buckling behaviour of shear loaded composite panels with reinforced cutouts. Compos. Struct. 80: 1-9

Guo $\mathrm{Z}$ and Cheung 2008 Cutout reinforcements for shear loaded laminate and sandwich composite panels. Int. J. Mech. Mater. Des. 4: 157-171

$\mathrm{Hu}$ H-T and Lin B-H 1995 Buckling optimization of symmetrically laminated plates with various geometries and end conditions. Comp. Sci. Technol. 55: 277-285

Hu H-T and Chen Z-Z 1999 Buckling optimization of unsymmetrically laminated plates under transverse loads. Struct. Eng. Mech. 7: 19-33 
Hu H, Badir A and Abatan A 2003 Buckling behavior of graphite/epoxy composite plate under parabolic variation of axial loads. Int. J. Mech. Sci. 45: 1135-1147

Husam A Q, Hasan K and Hazim D 2009 Assessment of the buckling bahaviour of square composite plates with circular cutout subjected to in-plane shear. Jordan J. Civ. Eng. 3: 184-195

Jain P and Ashwin K 2004 Post buckling response of square laminates with a central circular/elliptical cutout. Compos. Struct. 65: 179-185

Jana P and Bhaskar K 2006 Stability analysis of simply-supported rectangular plates under non-uniform uniaxial compression using rigorous and approximate plane stress solutions. Thin-Walled Struct. 44: $507-516$

Jones R M 1999 Mechanics of composite material. Taylor and Francis

Kang J-H and Leissa A W 2005 Exact solutions for the buckling of rectangular plates having linearly varying in-plane loading on two opposite simply supported edges

Leissa A W and Kang J-H 2002 Exact solutions for vibration and buckling of an SS-C-SS-C rectangular plate loaded by linearly varying in-plane stresses. Int. J. Mech. Sci. 44: 1925-1945

Nemeth M P 1997 Buckling behavior of long symmetrically laminated plates subjected to shear and linearly varying edge loads. NASA TP-3659

Panda S K and Ramachandra L S 2010 Buckling of rectangular plates with various boundary conditions loaded by non-uniform inplane loads. Int. J. Mech. Sci. 52: 819-828

Shufrin I, Rabinovitch O and Eisenberger M 2008a Buckling of laminated plates with general boundary conditions under combined compression, tension and shear- A semi-analytical solution. Thin-Walled Struct. 46: 925-938

Shufrin I, Rabinovitch O and Eisenberger M 2008b Buckling of symmetrically laminated rectangular plates with general boundary conditions-A semi analytical approach. Compos. Struct. 82: 521-531

Singh S B and Ashwin K 1998 Postbuckling response and failure of symmetric laminates under in-plane shear. Comp. Sci. Technol. 58: 1949-1960

Srivatsa K S and Murthy K 1992 Stability of laminated composite plates with cutouts. Comput. Struct. 43: 273-279

Topal U and Uzman U 2008 Maximization of buckling load of laminated composite plates with central circular holes using MFD method. Struct. Multidisc. Optom. 35: 131-139

Zhang Y X and Yang C H 2009 Recent developments in finite element analysis for laminated composite plates. Compos. Struct. 88: 147-157

Zhong H and Gu C 2007 Buckling of symmetrical cross-ply composite rectangular plates under a linearly varying in-plane load. Compos. Struct. 80: 42-48 